\title{
Kalirin-7 is a Key Player in the Formation of Excitatory Synapses in Hippocampal Neurons
}

\author{
Xin-Ming Ma \\ Department of Neuroscience, University of Connecticut Health Center, Farmington \\ E-mail: Ma@nso.uchc.edu \\ Received May 14, 2010; Revised June 26, 2010; Accepted June 28, 2010; Published August 17, 2010
}

\begin{abstract}
Kalirin-7 (Kal7), a major isoform of Kalirin in the adult rodent hippocampus, is exclusively localized to the postsynaptic side of mature excitatory synapses in hippocampal neurons. Kal7 interacts with multiple PDZ domain-containing proteins through its unique PDZ binding motif. Overexpression of Kal7 increases spine density and spine size, whereas reduction of endogenous Kal7 expression by small hairpin RNA (shRNA) causes a decrease in synapse number and spine density in cultured hippocampal neurons. Hippocampal CA1 pyramidal neurons of Kal7 knockout $\left(\mathrm{Kal} 7^{\mathrm{KO}}\right)$ mice show decreased spine density, spine length, synapse number, and postsynaptic density (PSD) size in their apical dendrites; are deficient in long-term potentiation (LTP); and exhibit decreased frequency of spontaneous excitatory postsynaptic current (sEPSC). Kal7 plays a key role in estrogen-mediated spine/synapse formation in hippocampal neurons. Kal7 is also an essential determinant of dendritic spine formation following chronic cocaine treatment. Kal7 plays a key role in excitatory synapse formation and function.
\end{abstract}

KEYWORDS: synaptogenesis, dendritic spine, plasticity, estrogen, cocaine, Rho GEF, postsynaptic density

\section{UNDERSTANDING THE UNDERLYING MOLECULAR MECHANISMS OF SYNAPTOGENESIS IS OF GREAT INTEREST}

The majority of excitatory glutamatergic synapses are localized on dendritic spines, which are small protrusions from the dendritic arbor in the brain[1]. Dendritic spines, which are highly dynamic and have very diverse morphology, are believed to constitute a structural substrate of memory[2]. Changes in synaptic plasticity are often related to the changes in spine density and spine size[3,4]. Increases in both spine number[5,6] and spine size[7,8] contribute to long-term potentiation (LTP) and are associated with learning and memory mechanisms $[9,10,11,12]$. Larger spines contain more AMPA and NMDA receptors in the postsynaptic density (PSD), and spine head size and the number of presynaptic vesicles are well correlated with the size of the PSD[2]. Alterations in spine density, spine size, and excitatory synapse morphology are found in aging, in an enriched environment, after spatial training, after stress, and in some psychiatric and neurological diseases[13,14,15,16,17,18,19,20,21]. A better understanding of the underlying molecular mechanisms of synapse formation and development will contribute to our understanding of learning and memory, and facilitate the development of strategies for treating psychiatric and neurological diseases. 


\section{KALIRIN, A MULTIFUNCTIONAL PROTEIN, IS REQUIRED FOR SPINE FORMATION IN HIPPOCAMPAL CA1 PYRAMIDAL NEURONS}

Understanding spine plasticity requires understanding the factors that control the actin cytoskeleton[22,23]. Rho GTPases, which are activated by Rho guanine nucleotide exchange factors (GEFs) and inactivated by Rho GTPase activating proteins (GAPs), are important intracellular signaling switches in the regulation of cytoskeletal organization[23,24,25,26]. The constitutive activation or inactivation of GEFs is a cause of human disease and a handful of GEFs have been found to be mutated in human cancers[24]. Kalirin, a Rho GEF, activates Rac1, RhoA, and RhoG[27,28,29,30,31,32,33,34]. Alternative splicing of the Kalirin gene and the use of multiple promoters generate at least 10 alternatively spliced isoforms encoding functionally distinct proteins that are expressed in a tissue-specific and developmentally regulated manner[35,36,37,38] (Fig. 1). Kalirin is highly expressed in neurons in the central nervous system (CNS)[36]. The highest levels of Kalirin mRNA, as detected with a probe specific to a conserved spectrin region of all Kalirin isoforms, are found in the cerebral cortex, hippocampus, and Purkinje cells. Relatively high levels of expression are observed in the thalamus, caudate putamen, nucleus accumbens, amygdala, and anterior olfactory nucleus. Low levels of Kalirin mRNA are detected in the hypothalamus. Brain areas with high levels of Kalirin mRNA show strong Kalirin-like immunoreactivity (with an antibody specific to the spectrin region). In the hippocampus, Kalirin staining is observed in the soma and dendrites of the CA1-3 pyramidal cell layer, granule cells of the dentate gyrus, and scattered interneurons throughout the hippocampus[36]. Reduced expression of the most major Kalirin isoforms (Kal7, 9, and 12) causes simplification of the dendritic tree and a marked decrease of spine density, with dispersion of postsynaptic density markers and elimination of presynaptic endings in hippocampal CA1 pyramidal neurons[39]. Among these major Kalirin isoforms, Kal9 and Kal12 are highly expressed during embryonic development[30], and play an important role in axon outgrowth in rat sympathetic neurons[32]. Kal12 binding to dynamin 1 and dynamin 2 through its IgFn domain may play a role in coordinating Rho GTPase-mediated changes in the actin cytoskeleton with dynamin-mediated changes in membrane trafficking[40]. Strong Kal12 immunoreactivity was found in the growth cones of cultured hippocampal neurons (Ma et al., unpublished), suggesting a role for Kal12 in axon outgrowth. The functions of Kal9 and Kal12 in hippocampal neurons remain to be elucidated. The following is a brief summary of our current knowledge of Kal7, the major isoform of Kalirin in the adult rodent brain.

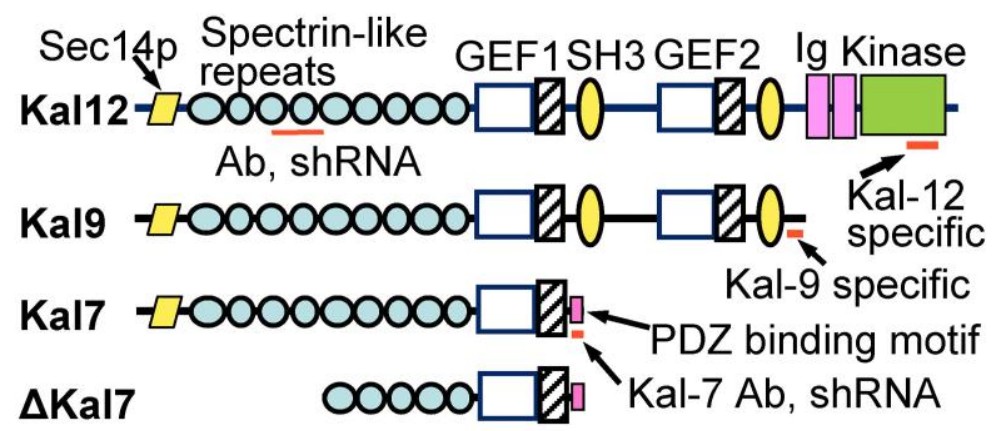

FIGURE 1. Alternative splicing generates different isoforms of Kalirin. The largest Kalirin isoform, Kal12, contains one Sec14p domain, nine spectrin-like repeats, two Rho GEF domains, two SH3 domains, two IgFn domains, and one serine/threonine kinase domain. Kal7 contains a unique PDZ binding motif. 


\section{KAL7 IS LOCALIZED TO THE POSTSYNAPTIC SIDE OF EXCITATORY SYNAPSES IN HIPPOCAMPAL NEURONS}

Kal7 is primarily expressed in neurons with a high level in the adult hippocampus[39]. Kal7 is distinguished from other Kalirin isoforms by its unique 20-amino-acid C-terminal PDZ binding motif, which allows Kal7 to interact with several PDZ domain-containing proteins[41] (Fig. 1). Kal7 mRNA and protein are found in CA1-3 pyramidal neurons, dentate granule cells, and interneurons scattered throughout the hippocampus[39]. Kal7 activates Rac1, which increases spine density and size[33,42]. Kal7 protein in the rodent hippocampus is undetectable at birth; its levels are extremely low at postnatal day (P) 7 and markedly increase at P14, a key time for synaptogenesis[39,43]. In cultured hippocampal neurons, Kal7-positive clusters are opposed to clusters of stained vesicular glutamate transporter 1 (Vglut1), a marker for excitatory presynaptic terminals (Fig. 2)[44]. Staining for Kal7 overlaps clusters of staining for PSD95 (a PSD marker for excitatory synapses), NMDA receptor subunits NR1 and NR2B, and AMPA receptor subunits GluR1 and GluR2 in both dendritic spines and shafts[44,45]. Synaptic activity regulates Kal7 expression in the postsynaptic side of excitatory synapses in hippocampal neurons because blocking the $\mathrm{GABA}_{\mathrm{A}}$ receptor with its antagonist bicuculline increases Kal7 levels in the synapses, accompanied by an increase in the number of excitatory synapses[45]. These data suggest that Kal7 might play an important role in the regulation of excitatory synapse formation.

\section{KAL7 INTERACTS WITH PROTEINS THAT PLAY A KEY ROLE IN SPINE/SYNAPTIC PLASTICITY}

Kal7 interacts with many proteins, such as PSD95, GluR1, NR1, SAP-102, SAP-97, chapsyn-110, neurabin, and spinophillin, in excitatory synapses[41,46]. These proteins play an important role in spine/synaptic plasticity, including assembling trafficking glutamate receptors, signaling complexes, and cytoskeletal remodeling of spines[47,48,49,50]. Kal7 also interacts with neuronal (N)-cadherin, Disruptedin-Schizophrenia 1 (DISC1), NGF receptor TrkA, and inducible nitric oxide synthase (iNOS) $28,46,51,52]$. The interaction of Kal7 and the small GTPase Arf6 suggests that Kal7 may play an important role in Arf6-mediated spine plasticity[53,54]. Kal7 is downstream of cyclin-dependent kinase-5 (Cdk5) and $\mathrm{Ca}^{2+} /$ calmodulin-dependent protein kinase II (CaMKII) and EphB[33,46,55]. Several key interactors of Kal7 are highlighted below.

- Cdk5 - Cdk5, a highly versatile kinase, plays a critical role in neurite extension, synaptic plasticity, the formation and function of dendritic spines, learning, and memory[56,57,58,59]. Cdk5 phosphorylates Kal7 at Thr1590, which is localized between the GEF domain and PDZ binding motif, and is the only Cdk5 phosphorylation site in Kal7[33]. Expression of Kal7 with an Ala1590 mutation (T/A, blocking phosphorylation site) causes a decrease in spine size, whereas expression of Kal7 with an Asp1590 mutation (T/D, mimicking phosphorylation) results in an increase in spine size in cultured neurons in comparison to expression of wild-type Kal7[33]. Both Kal7 T/A and T/D increase spine density as well as wild-type Kal7[33]. Alterations of spine size are implicated in learning and memory[12]. The levels of Cdk5 in the PSDs purified from the hippocampus in $\mathrm{Kal}^{\mathrm{KO}}$ mice decrease compared to their wild-type controls[60]. These data suggest that $\mathrm{Cdk} 5$ regulates Kal7 function during synaptogenesis.

- CaMKII - CaMKII, the most abundant protein kinase in the mammalian brain, constitutes the major protein of the PSD in dendritic spines of excitatory neurons[61,62]. It is well established that CaMKII modulates synaptic plasticity, learning, and memory[62,63,64]. Phosphorylation of Kal7 by CaMKII may play an important role in synaptic activity-dependent enlargement of existing spines in cultured neurons[46]. 

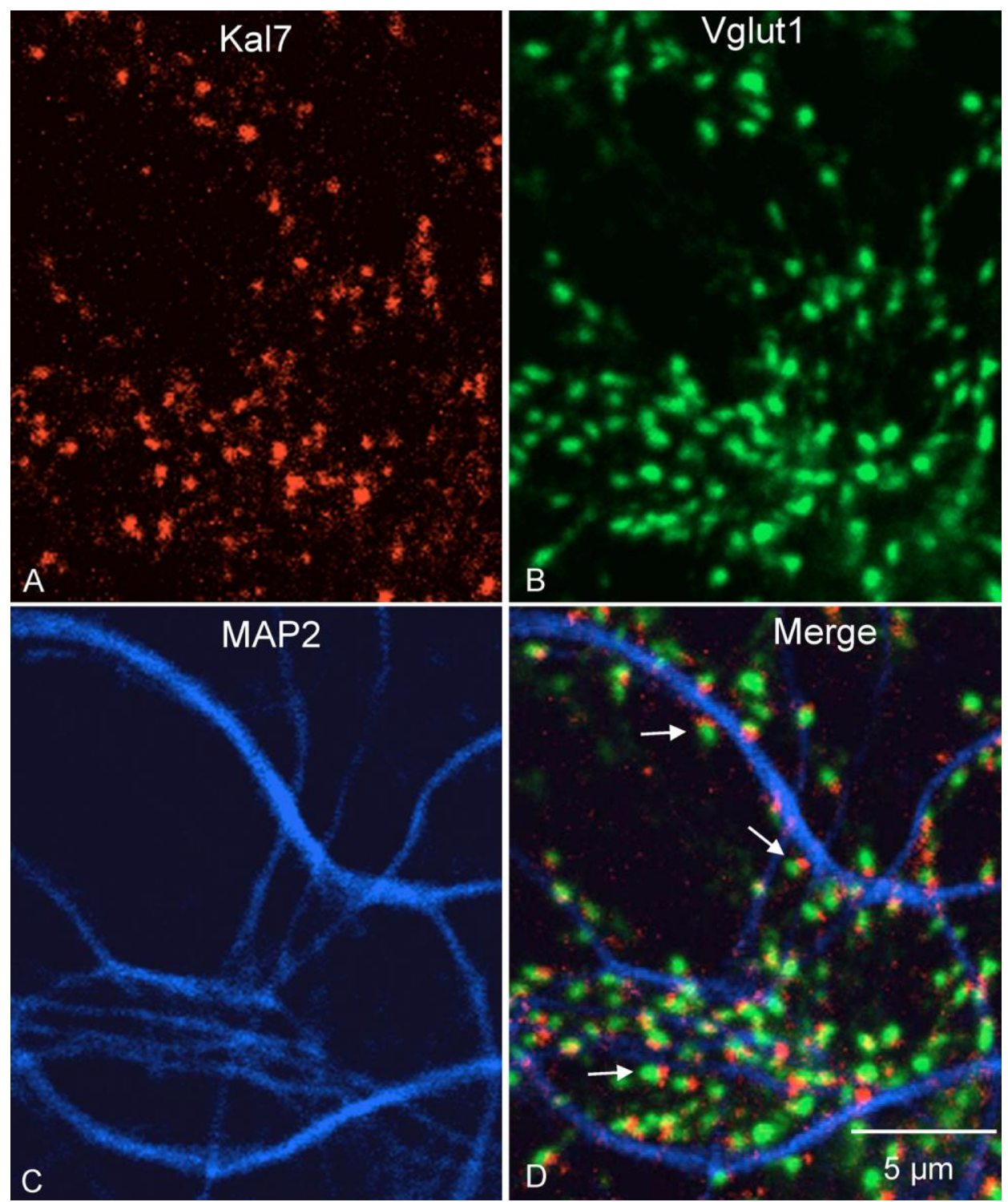

FIGURE 2. Kal7 is localized to the postsynaptic side of excitatory synapses in hippocampal neurons. The dendrites of mature hippocampal neurons (DIV30) were fixed with cold methanol and simultaneously stained for Kal7 (A, red), Vglut1 (B, green, a marker for excitatory presynaptic terminals), and MAP2 (C, blue, dendritic marker), showing that Kal7 is localized to the postsynaptic side of excitatory synapses (D, merge). Neuronal preparation and immunostaining were performed as described[44,45].

- N-Cadherin - The cadherin-catenin cell-adhesion complex plays a key role in both synapse formation and plasticity[65,66]. Kal7 interacts with N-cadherin[67]. In cultured neurons, Ncadherin and Kal7 colocalize at synapses, and Kal7 function is required for N-cadherindependent spine enlargement[67].

- DISC1 - Recent studies show that DISC1, a strong candidate susceptibility gene for schizophrenia, plays an important role in the regulation of synaptic plasticity[52,68,69]. Schizophrenia patients show a reduction in spine density on their cortical pyramidal neurons[70,71]. DISC1 colocalizes with Kal7 at dendritic spines, and regulates spine structure and function via Kal7. Overexpression of DISC1 causes a decrease in both spine density and spine size, while overexpression of a mutated DISC1, which does not bind to Kal7, does not alter 
spine density and spine size in cortical neurons in comparison to control neurons expressing GFP only[52].

- EphB - The receptor tyrosine kinase EphB and its membrane-bound ligand ephrinB play an important role in synapse formation and plasticity in the CNS[72,73]. EphB regulates Kal7 function through its phosphorylation of Kal7, and ephrinB-EphB receptor-induced activation of Kal7 causes an increase in the formation of dendritic spines in mature neurons[55].

\section{KAL7 IS REQUIRED FOR NORMAL SPINE/SYNAPSE FORMATION IN HIPPOCAMPAL PYRAMIDAL NEURONS IN VITRO AND IN VIVO}

Overexpression of Kal7 increases spine density and spine size in hippocampal pyramidal neurons[45] (Fig. 3). Reducing endogenous Kal7 expression by expressing a Kal7 shRNA causes a decrease in synapse number and spine density in cultured hippocampal pyramidal neurons[44,45]. Kal7 shRNAmediated reduction in spine density was accompanied by a decrease in the frequency of sEPSCs in these neurons (Lemtiri-Chlieh and Ma et al., unpublished). The Kal7 shRNA-induced decrease in spine density is rescued by simultaneous expression of exogenous Kal7 in cultured hippocampal neurons[45]. In addition, a recent interesting study shows that Kal7 is required for microRNA-stimulated spine formation in hippocampal neurons[74]. To evaluate the role of $\mathrm{Kal} 7$ in vivo, $\mathrm{Kal} 7^{\mathrm{KO}}$ mice were created; these mice grow and reproduce normally[60]. Spine density, spine length, PSD thickness, PSD length, and synapse number decrease in the apical dendrites of $\mathrm{Kal}^{\mathrm{KO}}$ hippocampal CA1 pyramidal neurons, which are deficient in LTP and exhibit a decrease in sEPSC frequency. These decreases may be due to decreased levels of NR2B and Cdk5 in the PSDs purified from the hippocampus of Kal $7^{\mathrm{KO}}$ mice. Importantly, deficits in spine formation in $\mathrm{Kal}^{\mathrm{KO}}$ neurons are rescued by exogenous Kal7[60]. Similarly, a recent study reports that Kal7 plays a key role in spine formation in cortical neurons[75]. These studies show that Kal7 is essential for normal excitatory synapse formation[60,76].

\section{KAL7 PLAYS A KEY ROLE IN EXCITATORY SYNAPSE FORMATION IN HIPPOCAMPAL INTERNEURONS}

Hippocampal interneurons, which are free of dendritic spines, play an essential role in maintaining normal circuits in the CNS, which requires a delicate balance between synaptic excitation and inhibition[77,78]. Low levels of Kal7 are detected at the postsynaptic side of excitatory synapses on the dendritic shaft of hippocampal interneurons[44]. Overexpression of Kal7 increases dendritic branching, and induces the formation of dendritic spines along the dendrites and on the soma of normally aspiny hippocampal interneurons, whereas reducing endogenous Kal7 by shRNA results in a decrease in the number of excitatory synapses on the dendritic shafts of these interneurons[44]. Disruption of interneuron development may contribute to development of psychiatric and neurological diseases [79,80,81]. These studies suggest a role of Kal7 in the development of these diseases.

\section{KAL7 PLAYS A KEY ROLE IN ESTROGEN-MEDIATED SPINE/SYNAPSE FORMATION IN HIPPOCAMPAL NEURONS}

Estrogen increases spine density and excitatory synapse number in both hippocampal CA1 pyramidal neurons of ovariectomized rats in vivo and cultured hippocampal neurons in vitro[45,82,83]. Spine density[84] and spine size[85] in CA1 pyramidal neurons change across the estrous cycle, peaking during proestrous with its high estrogen levels. However, the underlying mechanisms of estrogen-mediated spine formation are not fully understood. Estrogen replacement increases the intensity of Kal7 staining in both 


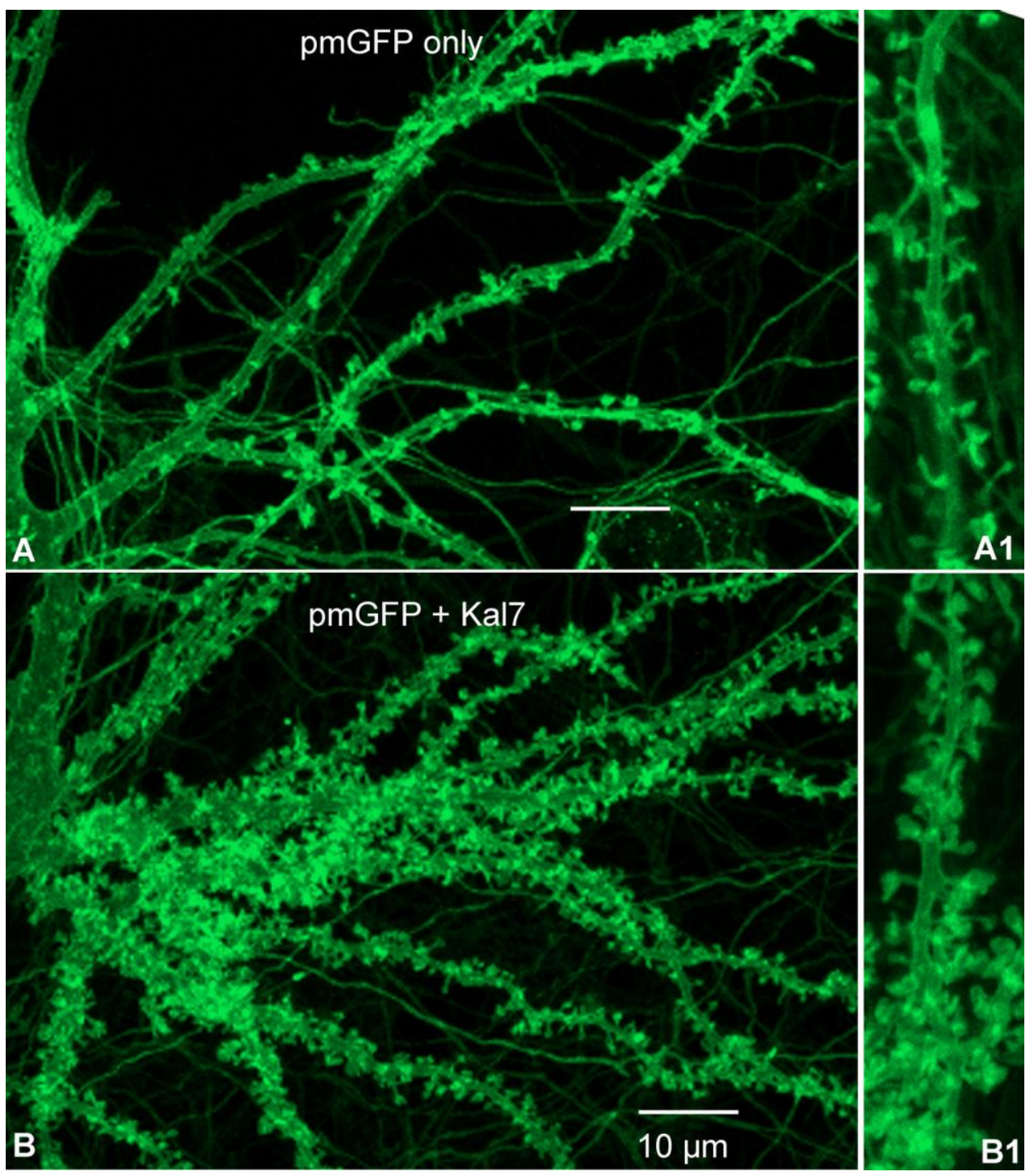

FIGURE 3. Kal7 increases spine density in cultured hippocampal neurons when overexpressed. Hippocampal neurons prepared from postnatal day 1 rat pups were transfected with a vector encoding a membrane-tethered version of GFP (pmGFP) alone (A, A1), or vectors encoding both pmGFP and myc-Kal7 in a 1:2 ratio (B, B1) as described[45]. Z-step $(0.2 \mu \mathrm{m})$ images of live cells were taken at DIV16 with a Zeiss LSM 510 confocal microscope. Expression of Kal7 was verified by Myc staining as described (not shown)[45]. A1 and B1 are high-power images from A and B, respectively. Neuronal preparation, transfection, and immunostaining were performed as described[44,45].

CA1 pyramidal neurons and interneurons in ovariectomized F-344 rats[45]. Estrogen treatment causes an increase in both Kal7 levels at the postsynaptic side of excitatory synapses and in the number of excitatory synapses along the dendrites of pyramidal neurons in cultured hippocampal neurons[45]. The density of excitatory synapses is reduced and estrogen treatment is no longer able to increase synapse formation in hippocampal neurons when endogenous Kal7 expression is reduced using a Kal7-specific shRNA, suggesting a key role of Kal7 in the estrogen-mediated formation of excitatory synapses[45]. 


\section{KAL7 PLAYS AN ESSENTIAL ROLE IN SPINE FORMATION FOLLOWING CHRONIC COCAINE TREATMENT}

Kal7-mediated spine formation is not specific to hippocampal neurons. Kal7 is expressed in medium spiny neurons of the nucleus accumbens, a brain region involved in drug addiction. Overexpression of Kal7 caused an increase in spine density and spine size, whereas reducing endogenous Kal7 levels caused a decrease in spine density in medium spiny neurons in slice cultures of the nucleus accumbens (Ma et al., unpublished). Chronic cocaine treatment results in a long-lasting increase in dendritic spine density in the nucleus accumbens, but the molecular mechanisms underlying this morphological change are not understood[86]. Repeated cocaine treatment, which increases Kal7 levels in the nucleus accumbens, causes a robust increase in dendritic spine density in medium spiny neurons of the nucleus accumbens core in wild-type mice, but not in $\mathrm{Kal} 7^{\mathrm{KO}}$ mice. In behavioral tests, Kal $7^{\mathrm{KO}}$ mice show increased locomotor sensitization in comparison to wild-type controls[87]. Enhanced sensitivity to cocaine in $\mathrm{Kal}^{\mathrm{KO}}$ mice suggests that the increase in dendritic spines, normally seen after repeated cocaine, is protective and helps to prevent even more locomotor activity if the spines had not increased. This may also correlate with the decrease in Cdk5 and NR2B seen in Kal7 ${ }^{\mathrm{KO}}$ mice[60], since lowered Cdk5 and NR2B both enhance locomotor sensitization to stimulant[88,89]. In conclusion, Kal7 plays an essential role in chronic cocaine treatment-induced spine formation, and is necessary for the normal behavioral response to cocaine.

\section{KAL7 MAY BE RELATED TO PSYCHIATRIC AND NEUROLOGICAL DISEASES}

Dendritic spine density and/or spine morphology are altered in psychiatric and neurological diseases, and recent studies suggest a role for Kal7 and its interactors in specific diseases[20,90,91,92,93,94,95]. Kalirin expression increases in the rat hippocampus after electroconvulsive shock, an animal model for electroconvulsive treatment (ECT), an effective therapy for drug-refractory depression[96,97]. Spine density decreases in the hippocampus in animal models of depression[98] and ECT treatment causes an increase in synapse number in hippocampal neurons [99]. These studies suggest that Kal7 may play a role in the ECT-induced increase in synapse number and, thus, in ECT therapy for depression. Several clinical studies suggest that alterations in Kalirin expression may lead to disease. Neuropsychiatric disease is associated with reduced excitatory synaptic connectivity[100,101]. Decreased Kalirin levels are accompanied by a decrease in spine density in the cortex of schizophrenic patients[70,71,102]. Kal7 ${ }^{\mathrm{KO}}$ mice show decreased anxiety-like behavior and impaired acquisition of a passive avoidance task[60]. Kalirin $^{\mathrm{KO}}$ (deletion of major Kalirin isoforms) mice exhibit locomotor hyperactivity and deficits in working memory, sociability, and prepulse inhibition[60,75]. These behaviors are similar to those described for neuropsychiatric disease[103,104,105]. Disturbances in the DISC1-Kal-7 complexmediated synaptic maintenance may contribute to the onset of neuropsychiatric disease[52]. Kalirin levels are decreased in the hippocampus of Alzheimer's disease patients[106,107]. The interaction of Kalirin and huntingtin-associated protein 1 (HAP1) suggests that Kalirin is relevant to Huntington's disease[108]. High levels of Kal7 are found in the CA2-3 hippocampal areas, which are relatively ischemia resistant, suggesting a role of Kal7 in the regulation of ischemic signal transduction[109]. A more recent study indicates that Kalirin is a novel genetic risk factor for ischemic stroke[110].

\section{CONCLUSIONS AND FUTURE DIRECTIONS}

Kal7 is required for synapse formation and function in hippocampal neurons in vitro and in vivo. Kal7 plays a key role in the mechanisms of spine/synapse formation induced by estrogen and chronic cocaine exposure. Future studies will investigate the underlying molecular mechanisms of Kal7-mediated spine/synapse formation and its contributions to learning and memory, and determine the role of Kal7 in 
the development of psychiatric and neurological diseases in which normal dendritic spines are altered. Conditional gene deletion approaches will be used to alter Kal7 expression in specific areas or neuronal subpopulations, such as hippocampal CA1 region and nucleus accumbens core.

\section{ACKNOWLEDGMENTS}

This work was supported by grants DK32948, DA22876, and MH086552 from the NIH. Thanks to Drs. Betty Eipper, Dick Mains, Zhao-wen Wang, and William Shoemaker for their critical readings and comments.

\section{REFERENCES}

1. Harris, K.M. and Kater, S.B. (1994) Dendritic spines: cellular specializations imparting both stability and flexibility to synaptic function. Annu. Rev. Neurosci. 17, 341-371.

2. Bourne, J.N. and Harris, K.M. (2008) Balancing structure and function at hippocampal dendritic spines. Annu. Rev. Neurosci. 31, 47-67.

3. Chen, L.Y., Rex, C.S., Casale, M.S., Gall, C.M., and Lynch, G. (2007) Changes in synaptic morphology accompany actin signaling during LTP. J. Neurosci. 27, 5363-5372.

4. Yang, Y. and Zhou, Q. (2009) Spine modifications associated with long-term potentiation. Neuroscientist 15, 464476.

5. Engert, F. and Bonhoeffer, T. (1999) Dendritic spine changes associated with hippocampal long-term synaptic plasticity. Nature 399, 66-70.

6. Maletic-Savatic, M., Malinow, R., and Svoboda, K. (1999) Rapid dendritic morphogenesis in CA1 hippocampal dendrites induced by synaptic activity. Science 283, 1923-1927.

7. Matsuzaki, M., Honkura, N., Ellis-Davies, G.C., and Kasai, H. (2004) Structural basis of long-term potentiation in single dendritic spines. Nature 429, 761-766.

8. Yang, Y., Wang, X.B., Frerking, M., and Zhou, Q. (2008) Spine expansion and stabilization associated with longterm potentiation. J. Neurosci. 28, 5740-5751.

9. Kasai, H., Matsuzaki, M., Noguchi, J., Yasumatsu, N., and Nakahara, H. (2003) Structure-stability-function relationships of dendritic spines. Trends Neurosci. 26, 360-368.

10. Leuner, B. and Shors, T.J. (2004) New spines, new memories. Mol. Neurobiol. 29, 117-130.

11. Malenka, R.C. and Bear, M.F. (2004) LTP and LTD: an embarrassment of riches. Neuron 44, 5-21.

12. De Roo, M., Klauser, P., Garcia, P.M., Poglia, L., and Muller, D. (2008) Spine dynamics and synapse remodeling during LTP and memory processes. Prog. Brain Res. 169, 199-207.

13. Moser, M.B., Trommald, M., and Andersen, P. (1994) An increase in dendritic spine density on hippocampal CA1 pyramidal cells following spatial learning in adult rats suggests the formation of new synapses. Proc. Natl. Acad. Sci. U. S. A. 91, 12673-12675.

14. Berman, R.F., Hannigan, J.H., Sperry, M.A., and Zajac, C.S. (1996) Prenatal alcohol exposure and the effects of environmental enrichment on hippocampal dendritic spine density. Alcohol 13, 209-216.

15. Fiala, J.C., Spacek, J., and Harris, K.M. (2002) Dendritic spine pathology: cause or consequence of neurological disorders? Brain Res. Brain Res. Rev. 39, 29-54.

16. Blanpied, T.A. and Ehlers, M.D. (2004) Microanatomy of dendritic spines: emerging principles of synaptic pathology in psychiatric and neurological disease. Biol. Psychiatry 55, 1121-1127.

17. Radley, J.J. and Morrison, J.H. (2005) Repeated stress and structural plasticity in the brain. Ageing Res. Rev. 4, 271287.

18. Long, L.H., Liu, R.L., Wang, F., Liu, J., Hu, Z.L., Xie, N., Jin, Y., Fu, H., and Chen, J.G. (2009) Age-related synaptic changes in the CA1 stratum radiatum and spatial learning impairment in rats. Clin. Exp. Pharmacol. Physiol. 36, 675-681.

19. von Bohlen Und Halbach, O. (2009) Structure and function of dendritic spines within the hippocampus. Ann. Anat. 191, 518-531.

20. van Spronsen, M. and Hoogenraad, C.C. (2010) Synapse pathology in psychiatric and neurologic disease. Curr. Neurol. Neurosci. Rep. 10, 207-214.

21. Burke, S.N. and Barnes, C.A. (2010) Senescent synapses and hippocampal circuit dynamics. Trends Neurosci. 33, 153-161.

22. Schmidt, A. and Hall, M.N. (1998) Signaling to the actin cytoskeleton. Annu. Rev. Cell Dev. Biol. 14, $305-338$.

23. Luo, L. (2002) Actin cytoskeleton regulation in neuronal morphogenesis and structural plasticity. Annu. Rev. Cell Dev. Biol. 18, 601-635. 
24. Rossman, K.L., Der, C.J., and Sondek, J. (2005) GEF means go: turning on RHO GTPases with guanine nucleotideexchange factors. Nat. Rev. Mol. Cell Biol. 6, 167-180.

25. Yeh, B.J., Rutigliano, R.J., Deb, A., Bar-Sagi, D., and Lim, W.A. (2007) Rewiring cellular morphology pathways with synthetic guanine nucleotide exchange factors. Nature 447, 596-600.

26. Saneyoshi, T., Fortin, D.A., and Soderling, T.R. (2010) Regulation of spine and synapse formation by activitydependent intracellular signaling pathways. Curr. Opin. Neurobiol. 20, 108-115.

27. Mains, R.E., Alam, M.R., Johnson, R.C., Darlington, D.N., Back, N., Hand, T.A., and Eipper, B.A. (1999) Kalirin, a multifunctional PAM COOH-terminal domain interactor protein, affects cytoskeletal organization and ACTH secretion from AtT-20 cells. J. Biol. Chem. 274, 2929-2937.

28. Ratovitski, E.A., Alam, M.R., Quick, R.A., McMillan, A., Bao, C., Kozlovsky, C., Hand, T.A., Johnson, R.C., Mains, R.E., Eipper, B.A., and Lowenstein, C.J. (1999) Kalirin inhibition of inducible nitric-oxide synthase. J. Biol. Chem. 274, 993-999.

29. Alam, M.R., Steveson, T.C., Johnson, R.C., Back, N., Abraham, B., Mains, R.E., and Eipper, B.A. (2001) Signaling mediated by the cytosolic domain of peptidylglycine alpha-amidating monooxygenase. Mol. Biol. Cell 12, 629-644.

30. Hansel, D.E., Quinones, M.E., Ronnett, G.V., and Eipper, B.A. (2001) Kalirin, a GDP/GTP exchange factor of the Dbl family, is localized to nerve, muscle, and endocrine tissue during embryonic rat development. J. Histochem. Cytochem. 49, 833-844.

31. Rabiner, C.A., Mains, R.E., and Eipper, B.A. (2005) Kalirin: a dual Rho guanine nucleotide exchange factor that is so much more than the sum of its many parts. Neuroscientist 11, 148-160.

32. May, V., Schiller, M.R., Eipper, B.A., and Mains, R.E. (2002) Kalirin Dbl-homology guanine nucleotide exchange factor 1 domain initiates new axon outgrowths via RhoG-mediated mechanisms. J. Neurosci. 22, 6980-6990.

33. Xin, X., Wang, Y., Ma, X.M., Rompolas, P., Keutmann, H.T., Mains, R.E., and Eipper, B.A. (2008) Regulation of Kalirin by Cdk5. J. Cell Sci. 121, 2601-2611.

34. Ferraro, F., Ma, X.M., Sobota, J.A., Eipper, B.A., and Mains, R.E. (2007) Kalirin/Trio Rho guanine nucleotide exchange factors regulate a novel step in secretory granule maturation. Mol. Biol. Cell 18, 4813-4825.

35. Johnson, R.C., Penzes, P., Eipper, B.A., and Mains, R.E. (2000) Isoforms of kalirin, a neuronal Dbl family member, generated through use of different 5'- and 3'-ends along with an internal translational initiation site. J. Biol. Chem. 275, 19324-19333.

36. Ma, X.M., Johnson, R.C., Mains, R.E., and Eipper, B.A. (2001) Expression of kalirin, a neuronal GDP/GTP exchange factor of the trio family, in the central nervous system of the adult rat. J. Comp. Neurol. 429, 388-402.

37. McPherson, C.E., Eipper, B.A., and Mains, R.E. (2002) Genomic organization and differential expression of Kalirin isoforms. Gene 284, 41-51.

38. McPherson, C.E., Eipper, B.A., and Mains, R.E. (2004) Kalirin expression is regulated by multiple promoters. $J$. Mol. Neurosci. 22, 51-62.

39. Ma, X.M., Huang, J., Wang, Y., Eipper, B.A., and Mains, R.E. (2003) Kalirin, a multifunctional Rho guanine nucleotide exchange factor, is necessary for maintenance of hippocampal pyramidal neuron dendrites and dendritic spines. J. Neurosci. 23, 10593-10603.

40. Xin, X., Rabiner, C.A., Mains, R.E., and Eipper, B.A. (2009) Kalirin12 interacts with dynamin. BMC Neurosci. 10, 61.

41. Penzes, P., Johnson, R.C., Sattler, R., Zhang, X., Huganir, R.L., Kambampati, V., Mains, R.E., and Eipper, B.A. (2001) The neuronal Rho-GEF Kalirin-7 interacts with PDZ domain-containing proteins and regulates dendritic morphogenesis. Neuron 29, 229-242.

42. Newey, S.E., Velamoor, V., Govek, E.E., and Van Aelst, L. (2005) Rho GTPases, dendritic structure, and mental retardation. J. Neurobiol. 64, 58-74.

43. Steward, O. and Falk, P.M. (1991) Selective localization of polyribosomes beneath developing synapses: a quantitative analysis of the relationships between polyribosomes and developing synapses in the hippocampus and dentate gyrus. J. Comp. Neurol. 314, 545-557.

44. Ma, X.M., Wang, Y., Ferraro, F., Mains, R.E., and Eipper, B.A. (2008) Kalirin-7 is an essential component of both shaft and spine excitatory synapses in hippocampal interneurons. J. Neurosci. 28, 711-724.

45. Ma, X.M., Huang, J.P., Kim, E.J., Zhu, Q., Kuchel, G.A., Mains, R.E., and Eipper, B.A. (2010) Kalirin-7, an important component of excitatory synapses, is regulated by estradiol in hippocampal neurons. Hippocampus [Epub ahead of print]

46. Xie, Z., Srivastava, D.P., Photowala, H., Kai, L., Cahill, M.E., Woolfrey, K.M., Shum, C.Y., Surmeier, D.J., and Penzes, P. (2007) Kalirin-7 controls activity-dependent structural and functional plasticity of dendritic spines. Neuron 56, 640-656.

47. Sarrouilhe, D., di Tommaso, A., Metaye, T., and Ladeveze, V. (2006) Spinophilin: from partners to functions. Biochimie 88, 1099-1113.

48. Sheng, M. and Hoogenraad, C.C. (2007) The postsynaptic architecture of excitatory synapses: a more quantitative view. Annu. Rev. Biochem. 76, 823-847.

49. Feng, W. and Zhang, M. (2009) Organization and dynamics of PDZ-domain-related supramodules in the postsynaptic density. Nat. Rev. Neurosci. 10, 87-99. 
50. McKinney, R.A. (2010) Excitatory amino acid involvement in dendritic spine formation, maintenance and remodelling. J. Physiol. 588, 107-116.

51. Chakrabarti, K., Lin, R., Schiller, N.I., Wang, Y., Koubi, D., Fan, Y.X., Rudkin, B.B., Johnson, G.R., and Schiller, M.R. (2005) Critical role for Kalirin in nerve growth factor signaling through TrkA. Mol. Cell. Biol. 25, 5106-5118.

52. Hayashi-Takagi, A., Takaki, M., Graziane, N., Seshadri, S., Murdoch, H., Dunlop, A.J., Makino, Y., Seshadri, A.J., Ishizuka, K., Srivastava, D.P., Xie, Z., Baraban, J.M., Houslay, M.D., Tomoda, T., Brandon, N.J., Kamiya, A., Yan, Z., Penzes, P., and Sawa, A. (2010) Disrupted-in-Schizophrenia 1 (DISC1) regulates spines of the glutamate synapse via Rac1. Nat. Neurosci. 13, 327-332.

53. Koo, T.H., Eipper, B.A., and Donaldson, J.G. (2007) Arf6 recruits the Rac GEF Kalirin to the plasma membrane facilitating Rac activation. BMC Cell Biol. 8, 29.

54. Jaworski, J. (2007) ARF6 in the nervous system. Eur. J. Cell Biol. 86, 513-524.

55. Penzes, P., Beeser, A., Chernoff, J., Schiller, M.R., Eipper, B.A., Mains, R.E., and Huganir, R.L. (2003) Rapid induction of dendritic spine morphogenesis by trans-synaptic ephrinB-EphB receptor activation of the Rho-GEF kalirin. Neuron 37, 263-274.

56. Angelo, M., Plattner, F., and Giese, K.P. (2006) Cyclin-dependent kinase 5 in synaptic plasticity, learning and memory. J. Neurochem. 99, 353-370.

57. Fu, W.Y., Chen, Y., Sahin, M., Zhao, X.S., Shi, L., Bikoff, J.B., Lai, K.O., Yung, W.H., Fu, A.K., Greenberg, M.E., and Ip, N.Y. (2007) Cdk5 regulates EphA4-mediated dendritic spine retraction through an ephexin1-dependent mechanism. Nat. Neurosci. 10, 67-76.

58. Hawasli, A.H., Benavides, D.R., Nguyen, C., Kansy, J.W., Hayashi, K., Chambon, P., Greengard, P., Powell, C.M., Cooper, D.C., and Bibb, J.A. (2007) Cyclin-dependent kinase 5 governs learning and synaptic plasticity via control of NMDAR degradation. Nat. Neurosci. 10, 880-886.

59. Lai, K.O. and Ip, N.Y. (2009) Recent advances in understanding the roles of Cdk5 in synaptic plasticity. Biochim. Biophys. Acta 1792, 741-745.

60. Ma, X.M., Kiraly, D.D., Gaier, E.D., Wang, Y., Kim, E.J., Levine, E.S., Eipper, B.A., and Mains, R.E. (2008) Kalirin-7 is required for synaptic structure and function. J. Neurosci. 28, 12368-12382.

61. Kelly, P.T. (1991) Calmodulin-dependent protein kinase II. Multifunctional roles in neuronal differentiation and synaptic plasticity. Mol. Neurobiol. 5, 153-177.

62. Wayman, G.A., Lee, Y.S., Tokumitsu, H., Silva, A.J., and Soderling, T.R. (2008) Calmodulin-kinases: modulators of neuronal development and plasticity. Neuron 59, 914-931.

63. Dash, P.K., Moore, A.N., Kobori, N., and Runyan, J.D. (2007) Molecular activity underlying working memory. Learn. Mem. 14, 554-563.

64. Benfenati, F. (2007) Synaptic plasticity and the neurobiology of learning and memory. Acta Biomed. 78(Suppl. 1), 58-66.

65. Arikkath, J. and Reichardt, L.F. (2008) Cadherins and catenins at synapses: roles in synaptogenesis and synaptic plasticity. Trends Neurosci. 31, 487-494.

66. Tai, C.Y., Kim, S.A., and Schuman, E.M. (2008) Cadherins and synaptic plasticity. Curr. Opin. Cell Biol. 20, 567575.

67. Xie, Z., Photowala, H., Cahill, M.E., Srivastava, D.P., Woolfrey, K.M., Shum, C.Y., Huganir, R.L., and Penzes, P. (2008) Coordination of synaptic adhesion with dendritic spine remodeling by AF-6 and kalirin-7. J. Neurosci. 28, 6079-6091.

68. Kvajo, M., McKellar, H., Arguello, P.A., Drew, L.J., Moore, H., MacDermott, A.B., Karayiorgou, M., and Gogos, J.A. (2008) A mutation in mouse Disc1 that models a schizophrenia risk allele leads to specific alterations in neuronal architecture and cognition. Proc. Natl. Acad. Sci. U. S. A. 105, 7076-7081.

69. Brandon, N.J., Millar, J.K., Korth, C., Sive, H., Singh, K.K., and Sawa, A. (2009) Understanding the role of DISC1 in psychiatric disease and during normal development. J. Neurosci. 29, 12768-12775.

70. Glantz, L.A. and Lewis, D.A. (2000) Decreased dendritic spine density on prefrontal cortical pyramidal neurons in schizophrenia. Arch. Gen. Psychiatry 57, 65-73.

71. Garey, L.J., Ong, W.Y., Patel, T.S., Kanani, M., Davis, A., Mortimer, A.M., Barnes, T.R., and Hirsch, S.R. (1998) Reduced dendritic spine density on cerebral cortical pyramidal neurons in schizophrenia. J. Neurol. Neurosurg. Psychiatry 65, 446-453.

72. Klein, R. (2009) Bidirectional modulation of synaptic functions by Eph/ephrin signaling. Nat. Neurosci. 12, 15-20.

73. Lai, K.O. and Ip, N.Y. (2009) Synapse development and plasticity: roles of ephrin/Eph receptor signaling. Curr. Opin. Neurobiol. 19, 275-283.

74. Impey, S., Davare, M., Lasiek, A., Fortin, D., Ando, H., Varlamova, O., Obrietan, K., Soderling, T.R., Goodman, R.H., and Wayman, G.A. (2010) An activity-induced microRNA controls dendritic spine formation by regulating Rac1-PAK signaling. Mol. Cell. Neurosci. 43, 146-156.

75. Cahill, M.E., Xie, Z., Day, M., Barbolina, M.V., Miller, C.A., Weiss, C., Radulovic, J., Sweatt, J.D., Disterhoft, J.F., Surmeier, D.J., and Penzes, P. (2009) Kalirin regulates cortical spine morphogenesis and disease-related behavioral phenotypes. Proc. Natl. Acad. Sci. U. S. A. 106, 13058-13063.

76. Sommer, J.E. and Budreck, E.C. (2009) Kalirin-7: linking spine plasticity and behavior. J. Neurosci. 29 , 5367-5369. 
77. Maccaferri, G. and Lacaille, J.C. (2003) Interneuron Diversity series: hippocampal interneuron classifications-making things as simple as possible, not simpler. Trends Neurosci. 26, 564-571.

78. Lawrence, J.J. and McBain, C.J. (2003) Interneuron Diversity series: containing the detonation--feedforward inhibition in the CA3 hippocampus. Trends Neurosci. 26, 631-640.

79. Benes, F.M. and Berretta, S. (2001) GABAergic interneurons: implications for understanding schizophrenia and bipolar disorder. Neuropsychopharmacology 25, 1-27.

80. Powell, E.M., Campbell, D.B., Stanwood, G.D., Davis, C., Noebels, J.L., and Levitt, P. (2003) Genetic disruption of cortical interneuron development causes region- and GABA cell type-specific deficits, epilepsy, and behavioral dysfunction. J. Neurosci. 23, 622-631.

81. Ramos, B., Baglietto-Vargas, D., del Rio, J.C., Moreno-Gonzalez, I., Santa-Maria, C., Jimenez, S., Caballero, C., Lopez-Tellez, J.F., Khan, Z.U., Ruano, D., Gutierrez, A., and Vitorica, J. (2006) Early neuropathology of somatostatin/NPY GABAergic cells in the hippocampus of a PS1xAPP transgenic model of Alzheimer's disease. Neurobiol. Aging 27, 1658-1672.

82. Woolley, C.S. and McEwen, B.S. (1992) Estradiol mediates fluctuation in hippocampal synapse density during the estrous cycle in the adult rat. J. Neurosci. 12, 2549-2554.

83. Murphy, D.D., Cole, N.B., Greenberger, V., and Segal, M. (1998) Estradiol increases dendritic spine density by reducing GABA neurotransmission in hippocampal neurons. J. Neurosci. 18, 2550-2559.

84. Woolley, C.S., Gould, E., Frankfurt, M., and McEwen, B.S. (1990) Naturally occurring fluctuation in dendritic spine density on adult hippocampal pyramidal neurons. J. Neurosci. 10, 4035-4039.

85. Gonzalez-Burgos, I., Alejandre-Gomez, M., and Cervantes, M. (2005) Spine-type densities of hippocampal CA1 neurons vary in proestrus and estrus rats. Neurosci. Lett. 379, 52-54.

86. Robinson, T.E. and Kolb, B. (2004) Structural plasticity associated with exposure to drugs of abuse. Neuropharmacology 47(Suppl. 1), 33-46.

87. Kiraly, D.D., Ma, X.M., Mazzone, C.M., Xin, X., Mains, R.E., and Eipper, B.A. (2010) Behavioral and morphological responses to cocaine require Kalirin7. Biol. Psychiatry [Epub ahead of print]

88. Taylor, J.R., Lynch, W.J., Sanchez, H., Olausson, P., Nestler, E.J., and Bibb, J.A. (2007) Inhibition of Cdk5 in the nucleus accumbens enhances the locomotor-activating and incentive-motivational effects of cocaine. Proc. Natl. Acad. Sci. U. S. A. 104, 4147-4152.

89. Mao, L.M., Wang, W., Chu, X.P., Zhang, G.C., Liu, X.Y., Yang, Y.J., Haines, M., Papasian, C.J., Fibuch, E.E., Buch, S., Chen, J.G., and Wang, J.Q. (2009) Stability of surface NMDA receptors controls synaptic and behavioral adaptations to amphetamine. Nat. Neurosci. 12, 602-610.

90. Glantz, L.A. and Lewis, D.A. (2001) Dendritic spine density in schizophrenia and depression. Arch. Gen. Psychiatry 58, 203.

91. Spires, T.L., Grote, H.E., Garry, S., Cordery, P.M., Van Dellen, A., Blakemore, C., and Hannan, A.J. (2004) Dendritic spine pathology and deficits in experience-dependent dendritic plasticity in R6/1 Huntington's disease transgenic mice. Eur. J. Neurosci. 19, 2799-2807.

92. Zhou, Z., Hong, E.J., Cohen, S., Zhao, W.N., Ho, H.Y., Schmidt, L., Chen, W.G., Lin, Y., Savner, E., Griffith, E.C., Hu, L., Steen, J.A., Weitz, C.J., and Greenberg, M.E. (2006) Brain-specific phosphorylation of MeCP2 regulates activity-dependent Bdnf transcription, dendritic growth, and spine maturation. Neuron 52, 255-269.

93. Day, M., Wang, Z., Ding, J., An, X., Ingham, C.A., Shering, A.F., Wokosin, D., Ilijic, E., Sun, Z., Sampson, A.R., Mugnaini, E., Deutch, A.Y., Sesack, S.R., Arbuthnott, G.W., and Surmeier, D.J. (2006) Selective elimination of glutamatergic synapses on striatopallidal neurons in Parkinson disease models. Nat. Neurosci. 9, 251-259.

94. Pittenger, C. and Duman, R.S. (2008) Stress, depression, and neuroplasticity: a convergence of mechanisms. Neuropsychopharmacology 33, 88-109.

95. Knobloch, M. and Mansuy, I.M. (2008) Dendritic spine loss and synaptic alterations in Alzheimer's disease. Mol. Neurobiol. 37, 73-82.

96. Ma, X.M., Mains, R.E., and Eipper, B.A. (2002) Plasticity in hippocampal peptidergic systems induced by repeated electroconvulsive shock. Neuropsychopharmacology 27, 55-71.

97. Husain, M.M., McClintock, S.M., Rush, A.J., Knapp, R.G., Fink, M., Rummans, T.A., Rasmussen, K., Claassen, C., Petrides, G., Biggs, M.M., Mueller, M., Sampson, S., Bailine, S.H., Lisanby, S.H., and Kellner, C.H. (2008) The efficacy of acute electroconvulsive therapy in atypical depression. J. Clin. Psychiatry 69, 406-411.

98. Norrholm, S.D. and Ouimet, C.C. (2001) Altered dendritic spine density in animal models of depression and in response to antidepressant treatment. Synapse 42, 151-163.

99. Chen, F., Madsen, T.M., Wegener, G., and Nyengaard, J.R. (2009) Repeated electroconvulsive seizures increase the total number of synapses in adult male rat hippocampus. Eur. Neuropsychopharmacol. 19, 329-338.

100. McCullumsmith, R.E., Clinton, S.M., and Meador-Woodruff, J.H. (2004) Schizophrenia as a disorder of neuroplasticity. Int. Rev. Neurobiol. 59, 19-45.

101. Hayashi-Takagi, A. and Sawa, A. (2010) Disturbed synaptic connectivity in schizophrenia: convergence of genetic risk factors during neurodevelopment. Brain Res. Bull. [Epub ahead of print]

102. Hill, J.J., Hashimoto, T., and Lewis, D.A. (2006) Molecular mechanisms contributing to dendritic spine alterations in the prefrontal cortex of subjects with schizophrenia. Mol. Psychiatry 11, 557-566. 
103. Lipska, B.K. (2004) Using animal models to test a neurodevelopmental hypothesis of schizophrenia. J. Psychiatry Neurosci. 29, 282-286.

104. Le Pen, G., Grottick, A.J., Higgins, G.A., Martin, J.R., Jenck, F., and Moreau, J.L. (2000) Spatial and associative learning deficits induced by neonatal excitotoxic hippocampal damage in rats: further evaluation of an animal model of schizophrenia. Behav. Pharmacol. 11, 257-268.

105. Campanella, S. and Guerit, J.M. (2009) How clinical neurophysiology may contribute to the understanding of a psychiatric disease such as schizophrenia. Neurophysiol. Clin. 39, 31-39.

106. Youn, H.S., Jeoung, M.K., Koo, Y.B., Ji, H., Markesbery, W.R., Ji, I., and Ji, T.H. (2007) Kalirin is under-expressed in Alzheimer's disease hippocampus. J. Alzheimers Dis. 11, 385-397.

107. Youn, H., Ji, I., Ji, H.P., Markesbery, W.R., and Ji, T.H. (2007) Under-expression of Kalirin-7 Increases iNOS activity in cultured cells and correlates to elevated iNOS activity in Alzheimer's disease hippocampus. J. Alzheimers. Dis. 12, 271-281.

108. Colomer, V., Engelender, S., Sharp, A.H., Duan, K., Cooper, J.K., Lanahan, A., Lyford, G., Worley, P., and Ross, C.A. (1997) Huntingtin-associated protein 1 (HAP1) binds to a Trio-like polypeptide, with a rac1 guanine nucleotide exchange factor domain. Hum. Mol. Genet. 6, 1519-1525.

109. Beresewicz, M., Kowalczyk, J.E., and Zablocka, B. (2008) Kalirin-7, a protein enriched in postsynaptic density, is involved in ischemic signal transduction. Neurochem. Res. 33, 1789-1794.

110. Krug, T., Manso, H., Gouveia, L., Sobral, J., Xavier, J.M., Albergaria, I., Gaspar, G., Correia, M., Viana-Baptista, M., Simoes, R.M., Pinto, A.N., Taipa, R., Ferreira, C., Fontes, J.R., Silva, M.R., Gabriel, J.P., Matos, I., Lopes, G., Ferro, J.M., Vicente, A.M., and Oliveira, S.A. (2010) Kalirin: a novel genetic risk factor for ischemic stroke. Hum. Genet. 127, 513-523.

\section{This article should be cited as follows:}

Ma, X.-M. (2010) Kalirin-7 is a key player in the formation of excitatory synapses in hippocampal neurons. TheScientificWorldJOURNAL 10, 1655-1666. DOI 10.1100/tsw.2010.148. 

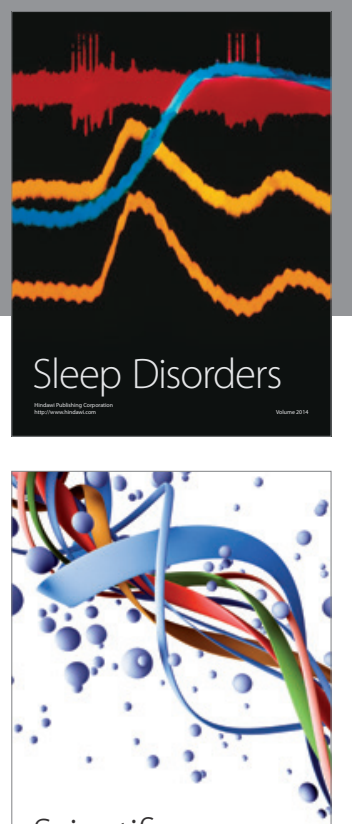

Scientifica
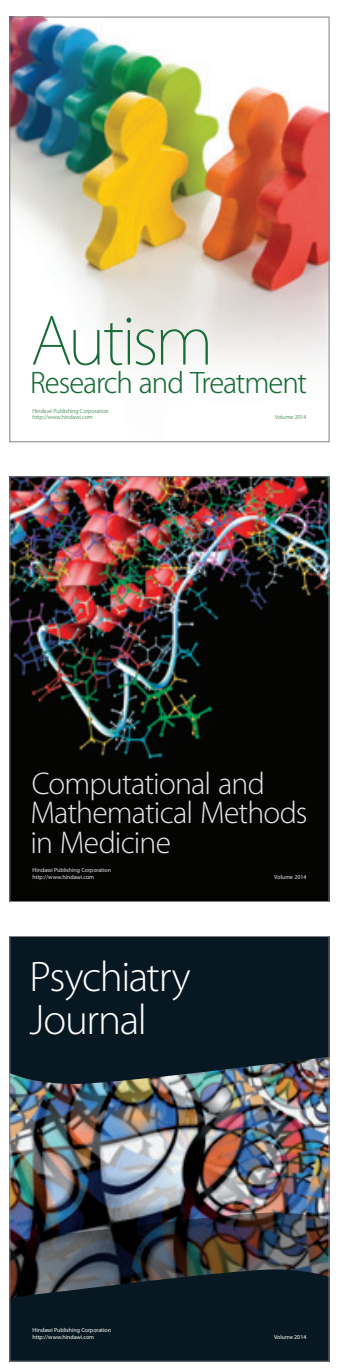
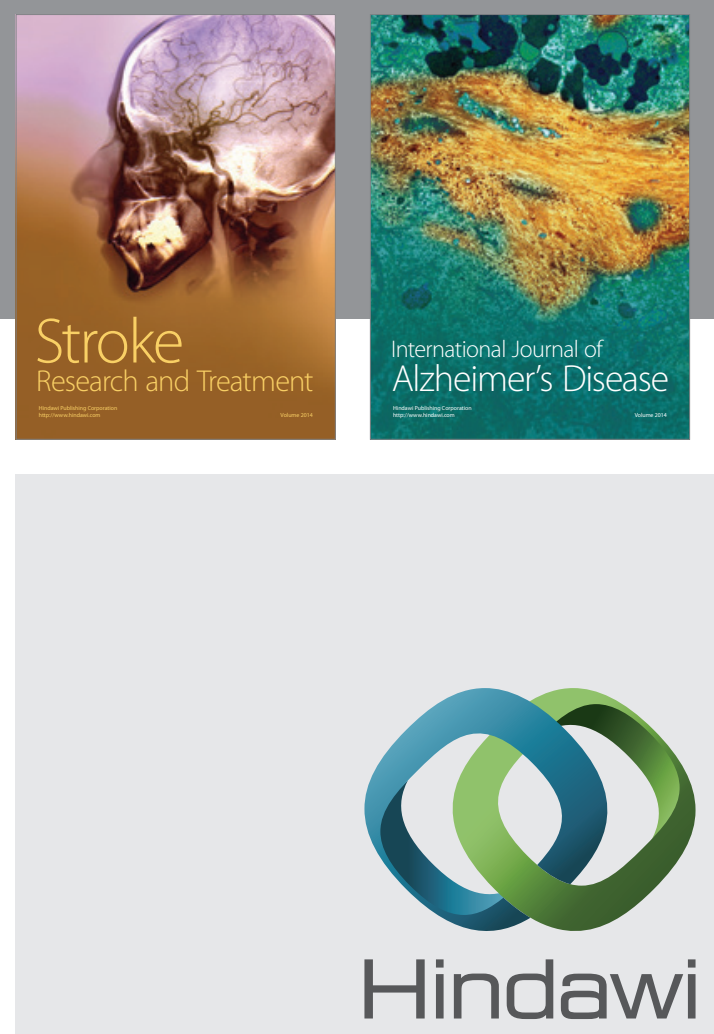

Submit your manuscripts at

http://www.hindawi.com
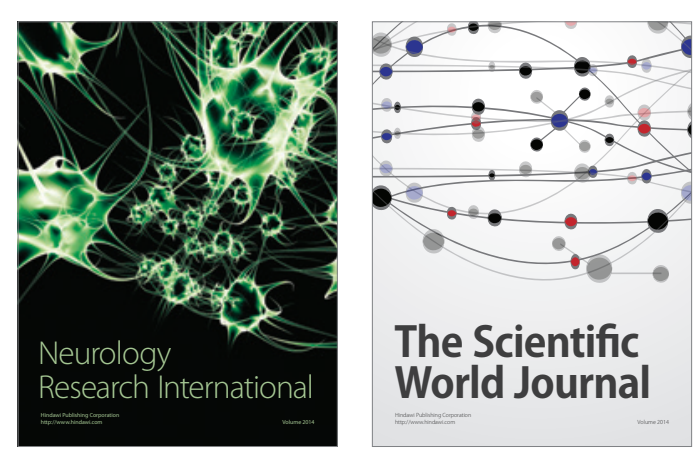

The Scientific World Journal

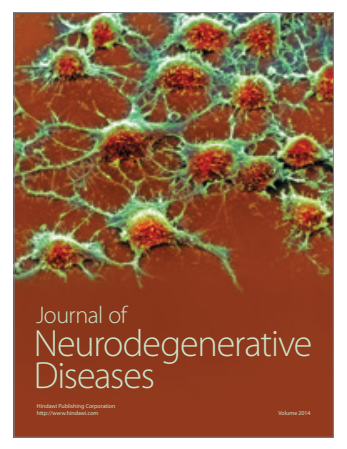

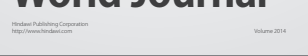

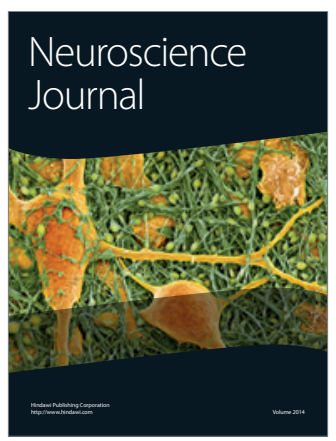

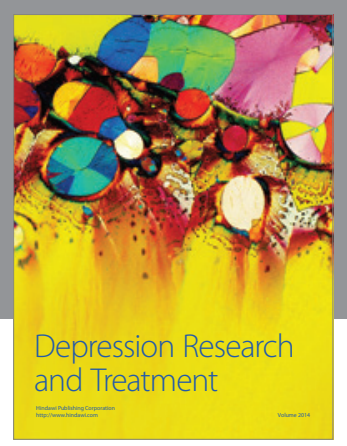
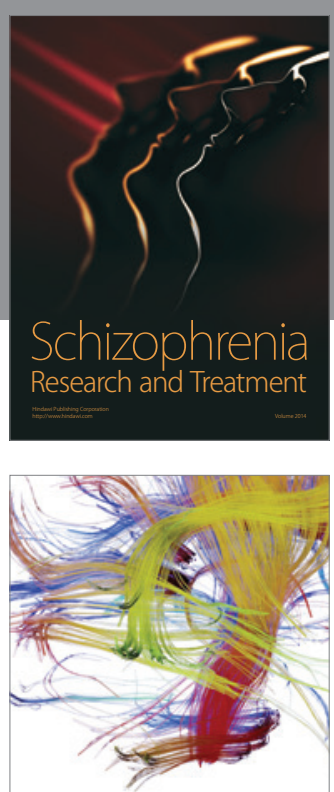

Brain Science

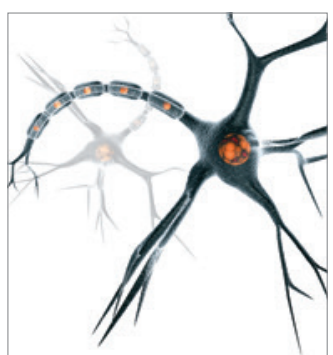

Neural Plasticity
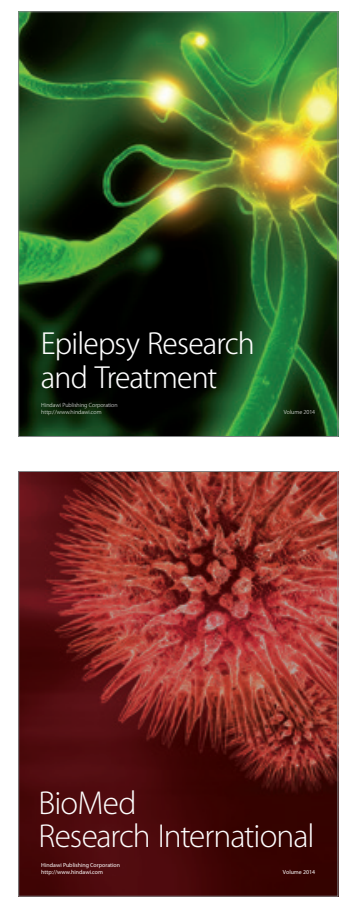

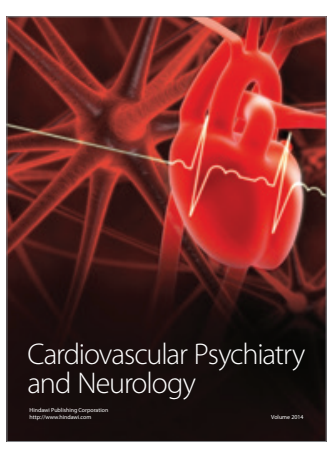

Parkinson's

Disease
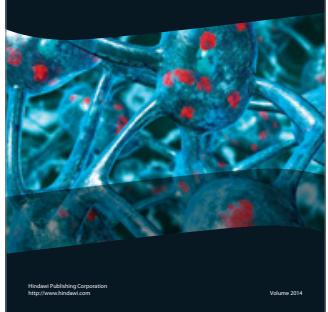